in vivo $31: 79-86(2017)$

doi:10.21873/invivo.11028

\title{
Influence of IL13 on Periostin Secretion by Synoviocytes in Osteoarthritis
}

\author{
TATSUYA MOUE, YUTARO TAJIKA, SHINTARO ISHIKAWA, YASUAKI KANADA, \\ TAKAYUKI OKUMO, KAZUHITO ASANO and TADASHI HISAMITSU \\ Department of Physiology, School of Medicine, Showa University, Tokyo, Japan
}

\begin{abstract}
Background: Our previous research provided evidence of periostin increase in parallel with interleukin-13 (IL13) increase in the synovial fluid of patients with osteoarthritis (OA). The reaction cascade from IL13 to periostin, however, remains unidentified. We, therefore, tested the hypothesis that periostin secretion is affected downstream of IL13. Materials and Methods: OA synoviocytes were cultured under different concentrations of IL13. Periostin content in culture supernatants and the level of signal transducer and activator of transcription 6 (STAT6) in the cultured cells were measured using enzyme-linked immunosorbent assay (ELISA). Moreover, the influence of dexamethasone and leflunomide on periostin production in relation to the effect of IL13 on the cells was also examined. Results: Periostin content in culture supernatants and the level of STAT6 in cultured cells were significantly increased by IL13. The increase of periostin was significantly inhibited by dexamethasone and leflunomide. Conclusion: Periostin may be up-regulated in OA synoviocytes via STAT6 downstream of IL13.
\end{abstract}

Osteoarthritis (OA) refers to the clinical syndrome of joint pain characterised by varying degrees of functional limitation and impaired quality of life. It is a leading cause of disability in the elderly and one of the leading causes of pain and disability worldwide. OA is the most common form of arthritis and most commonly affects the peripheral joints, particularly the knee. The number of patients with painful knee due to OA continues to increase dramatically with the aging of society: the estimated number of patients exceeds 25 million in the United States (1) and 8 million in Japan (2). The main

This article is freely accessible online.

Correspondence to: Shintaro Ishikawa, Department of Physiology, School of Medicine, Showa University, 1-5-8 Hatanodai, Shinagawa-ku, Tokyo 142-8555, Japan. Tel: +81 337848110, Fax: +81337845368, e-mail: s-ishikawa@med.showa-u.ac.jp

Key Words: Knee osteoarthritis, periostin, interleukin-13, IL13, signal transducer and activator of transcription 6, STAT6. symptom of OA is pain, which is also the leading factor for patients making lifestyle changes and seeking medical intervention (3). The objectives of OA management, according to OA Research Society International, are to reduce pain and inflammation, slow-down cartilage degradation, improve function, and reduce disability (4). Therefore, an important aspect is the discovery of an early-stage mediator of OA and the elucidation of an intracellular signal transduction system.

Periostin, also known as osteoblast-specific factor 2, is an extracellular matrix protein originally cloned from a mouse osteoblast cell line (5), and is implicated in the pathophysiology of tumour development, arthritis, atherosclerosis, and inflammatory diseases (6). The protein is a member of the transforming growth factor (TGF)- $\beta$-inducible protein superfamily and is induced in mesenchymal cells following stimulation by TGF- $\beta$, bone morphogenetic protein 2 , interleukin (IL)-4, or IL13 (7-9).

However, the inductive ligand varies according to the disorder. For instance, it is reported that IL13 may be a ligand in OA disorder (10). Our preliminary research provided evidence of increase of periostin expression in parallel with IL13 increase in synovial fluid of patients with OA (11). Furthermore, it became clear that the addition of periostin to OA fibroblasts promoted expression of several matrix metalloproteinases (MMPs). These results show that periostin secretion is related to tissue remodelling in OA. However, synovial fluid in arthrosis includes chondrocytes, adipocytes, and fibroblasts. Because our previous study used fibroblasts, the results do not reflect the reaction of the entire synovial tissue. Additionally, the reaction cascade from IL13 to periostin is still unidentified. Here, we aimed to demonstrate that periostin expression occurs downstream of IL13 and to clarify the reaction path and cascade from IL13 to periostin.

\section{Materials and Methods}

Materials. Human cryopreserved synoviocytes from a donor with OA (CDD-H-2910-OA) were purchased from Articular Engineering (Northbrook, IL, USA) and resuspended in Synoviocyte Growth Medium (M2700-HS; Articular Engineering). Recombinant human IL13 (IL13: 213-ILB) was purchased from R\&D Systems, Inc. 
(Minneapolis, MN, USA), dissolved in medium, sterilised by passing it through $0.2-\mu \mathrm{m}$ pore filters, and stored at $4^{\circ} \mathrm{C}$ until used The anti-inflammatory agent dexamethasone (041-18861) was purchased from Wako Pure Chemical Ind., Ltd. (Osaka, Japan). Leflunomide (L5025), an inhibitor of signal transducer and activator of transcription 6 (STAT6) was acquired from Sigma-Aldrich Co. LLC. (Saint Louis, MO, USA). Dexamethasone was diluted in ethanol in stock solutions at $10 \mathrm{mM}$ and stored in a freezer at $-20^{\circ} \mathrm{C}$ (12). Leflunomide was kept at $-4^{\circ} \mathrm{C}$ diluted in dimethyl sulfoxide (DMSO) at $30 \mathrm{mM}$ (13). The concentration of DMSO in the incubation media never exceeded $0.1 \%(\mathrm{v} / \mathrm{v})$, a condition that did not affect the cell survival rate.

Assay for periostin content in culture supernatants. OA synoviocytes were cultured at a density of $2 \times 10^{5}$ cells $/ \mathrm{ml}$ in the medium and cultured with different concentrations of IL13 in combination with/without dexamethasone (final concentration; $100 \mathrm{nM}$ ) or leflunomide (final concentration; $30 \mu \mathrm{M}$ ) in 24-well plates in triplicate. After culture supernatants were obtained and stored at $-80^{\circ} \mathrm{C}$ until use. Periostin content in culture supernatants was measured using a commercially available enzyme-linked immunosorbent assay (ELISA) kit (Phoenix Pharmaceuticals, Inc., Burlingame, CA, USA) according to the manufacturer's recommendations. The absorbance at $450 \mathrm{~nm}$ was measured by a Multiskan ${ }^{\mathrm{TM}}$ GO instrument (Thermo Fisher Scientific Inc. Waltham, MA, USA). The minimum detectable level of the ELISA kits was $0.14 \mathrm{ng} / \mathrm{ml}$ for human periostin.

Polymerase chain reaction (PCR) primers and reagent kits. The reagents used for mRNA isolation (TaqMan Gene Expression Cells-to$\mathrm{Ct}^{\mathrm{TM}}$ ) and real-time RT-PCR (TaqMan Gene Expression Assays) were purchased from Applied Biosystems (Foster City, CA, USA). These assays were performed according to the manufacturer's instructions (14). For real-time reverse transcription (RT)-PCR comparison of gene expression, we selected periostin (POSTN; TaqMan Gene Expression Assays; Assay ID: Hs01566743_m1). 18s, 18S ribosomal RNA (TaqMan Gene Expression Assays; Assay ID: Hs99999901_s1) was used as a housekeeping gene to normalise for RNA loading.

$m R N A$ isolation, quantitative RT-PCR. The OA synoviocytes were cultured at a density of $1 \times 10^{4}$ cells and with different concentrations of IL13 in combination with/without dexamethasone (final concentration; $100 \mathrm{nM}$ ) or leflunomide (final concentration; $30 \mu \mathrm{M}$ ) in 96-well plate in triplicate. Total RNA was isolated from the cells using $50 \mu$ Lysis Solution (P/N4383583). Each sample of total RNA was subjected to RT using 20× RT Enzyme Mix (P/N 4383585) and $2 \times$ RT Buffer (P/N43833586) with Applied Biosystems 2720 Thermal Cycler (Applied Biosystems). After the RT reaction, the cDNA templates were amplified by PCR using TaqMan Gene Expression Assays, PCR primers, and RT Master Mix (P/N 4369016). Predesigned and validated gene-specific TaqMan Gene Expression Assays $(14,15)$ from Applied Biosystems were used in duplicate for quantitative RT-PCR according to the manufacturer's protocol. PCR assays were performed as follows: 10 min denaturation at $95^{\circ} \mathrm{C}, 40$ cycles of $15 \mathrm{~s}$ denaturation at $95^{\circ} \mathrm{C}$, and $1 \mathrm{~min}$ annealing and extension at $60^{\circ} \mathrm{C}$. Samples were analyzed using an ABI Prism 7900HT Fast Real-Time PCR System (Applied Biosystems) $(15,16)$. Relative quantification (RQ) studies (17) were prepared from collected data (threshold cycle numbers, referred to as Ct) with ABI Prism 7900HT Sequence-Detection System (SDS) software 2.3 (Applied Biosystems).
Assay for STAT6 level in cultured cells. The OA synoviocytes were cultured at a density of $1 \times 10^{4}$ cells in 96-well microplate in triplicate and cultured with different concentrations of IL13 in combination with/without dexamethasone (final concentration; 100 $\mathrm{nM}$ ) or leflunomide (final concentration; $30 \mu \mathrm{M}$ ). The STAT6 level in the cultured cells was then measured with commercially available ELISA test kits (KCB3717; R\&D systems, Inc.) according to the manufacturer's recommendations. Details concerning the experimental procedure are given in the kit's instruction manual and are described only briefly here. The synoviocytes for experiments were fixed with $4 \%$ formaldehyde into each well of the 96 -well microplate. After the cells were bound with primary and secondary antibodies, fluorescence intensity was measured using a fluorescence plate reader (Twinkle LB970; Berthold Japan, Tokyo, Japan) with excitation at $540 \mathrm{~nm}$ and emission at $600 \mathrm{~nm}$, then read with excitation at $360 \mathrm{~nm}$ and emission at $450 \mathrm{~nm}$. The readings at $600 \mathrm{~nm}$ represented the amount of phosphorylated STAT6 in the cells, while readings at $450 \mathrm{~nm}$ represented the amount of total STAT6 in the cells. The fluorescence from the control wells was the background fluorescence and was subtracted from all sample wells. Ratios of phospho-STAT6/total STAT6 were expressed as normalised relative fluorescence units determined by dividing the phospho-STAT6 fluorescence at $600 \mathrm{~nm}$ by the total STAT6 fluorescence at $450 \mathrm{~nm}$ in each well.

Statistical analysis. Data are expressed as means \pm standard deviations. All assays were repeated twice to ensure reproducibility. Statistical significance of differences between the control and experimental groups was analysed by one-way analysis of variance followed by the Scheffe test. A probability $(p)$ value of less than 0.05 was considered statistically significant.

\section{Results}

Detection of periostin production by OA synoviocytes. Periostin in culture supernatant from OA synoviocytes in 24-well plates treated with IL13 was measured with commercially-available ELISA. Firstly, an IL13 dose-response curve was plotted using different concentrations for $24 \mathrm{~h}$ treatment; then a timeresponse curve was obtained using $10 \mathrm{ng} / \mathrm{ml} \mathrm{IL13} \mathrm{for} \mathrm{24,} 48$ and $72 \mathrm{~h}$. Periostin concentrations significantly increased at over $10 \mathrm{ng} / \mathrm{ml}$ and for intervals of $48 \mathrm{~h}$ or more (Figure 1). The experiments with the synoviocytes were carried out on the basis of these IL13 thresholds.

Next, we examined the influence of dexamethasone and leflunomide on periostin production induced by IL13 in these cells. Cells were treated with $100 \mathrm{nM}$ dexamethasone or $30 \mu \mathrm{M}$ leflunomide alone or in combination with 10 or 20 $\mathrm{ng} / \mathrm{ml}$ IL13. Controls with drug alone, and controls with lowdose IL13 treatment alone were included in the experiments. As shown in Figure 2, periostin production induced by IL13 was significantly inhibited by dexamethasone and leflunomide.

Detection of periostin mRNA expression in OA synoviocytes. Periostin mRNA extracted from OA synoviocytes, as above, was measured with quantitative RT-PCR. These experiments on the synoviocytes were carried out on the basis of the IL13 threshold 

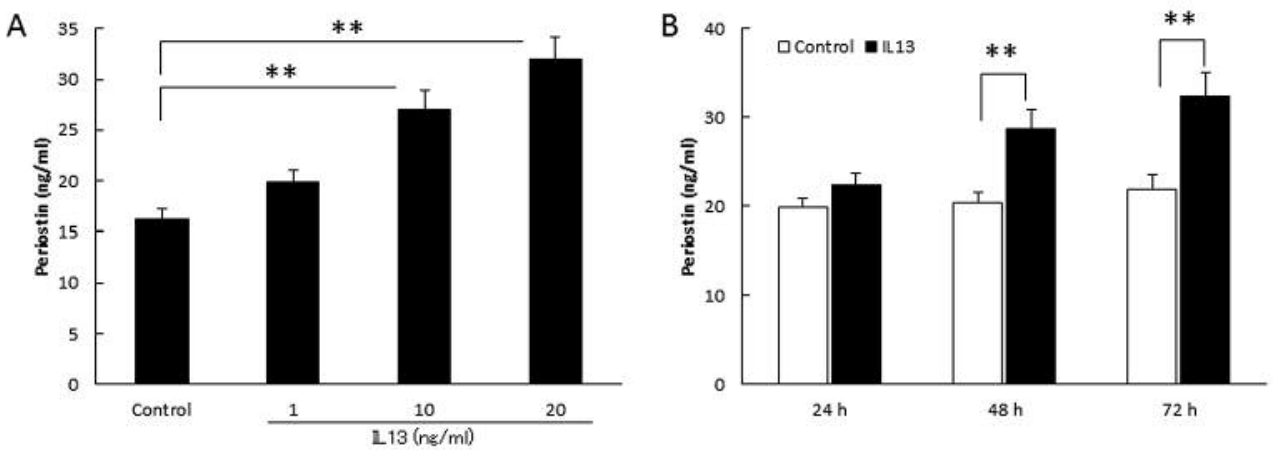

Figure 1. Effect of interleukin 13 (IL13) on periostin expression by osteoarthritis (OA) synoviocytes. Periostin in supernatant from cultured OA synoviocytes was measured with commercially available enzyme-linked immuno-sorbent assay. OA synoviocytes $\left(2 \times 10^{5} \mathrm{cells} / \mathrm{ml}\right)$ in $24-w e l l$ plates were treated with different concentrations of interleukin 13 (IL13) for $24 \mathrm{~h}$ to produce an IL13 dose-response curve (A), and with $10 \mathrm{ng} / \mathrm{ml}$ IL13 for different durations to produce the time-response curve $(B)$. Asterisks indicate statistically significant differences $(* * p<0.01)$. Error bars denote $\pm S D$.
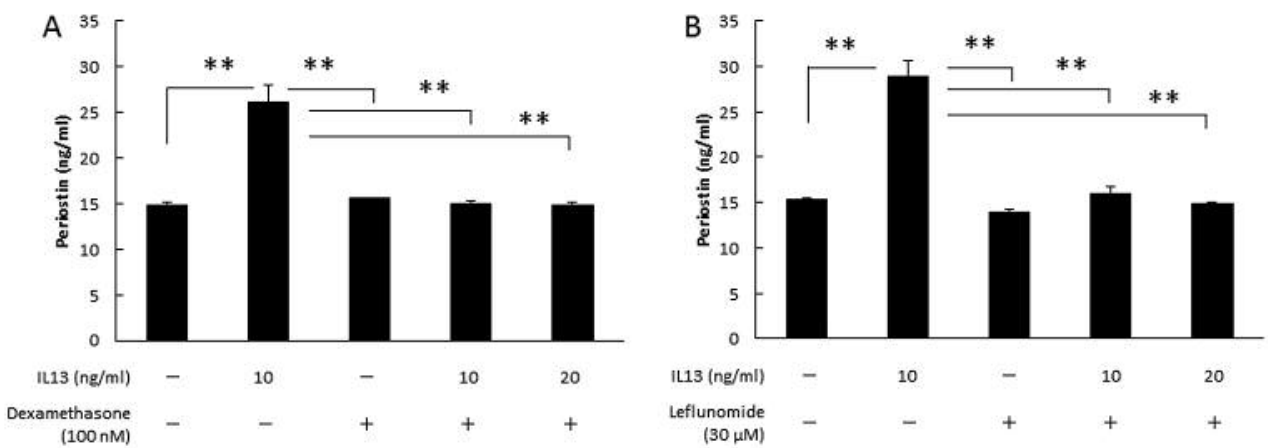

Figure 2. Influence of immunosuppressive agents on periostin protein production. The influence of anti-inflammatory dexamethasone (A) and signal transducer and activator of transcription 6 inhibitor leflunomide $(B)$ on periostin production in osteoarthritis (OA) synoviocytes was examined. Periostin in supernatant from cultured osteoarthritis $(O A)$ synoviocytes $\left(2 \times 10^{5} \mathrm{cells} / \mathrm{ml}\right)$ in 24 -well plateswith/without with IL13 and treated or not with agent was measured after $24 \mathrm{~h}$ with enzyme-linked immuno-sorbent assay. Asterisks indicate statistically significant differences (**p<0.01). Data are the means \pm SD.

for periostin product, using 10 and $20 \mathrm{ng} / \mathrm{ml} \mathrm{IL13} \mathrm{for} 24 \mathrm{~h}$, and showed that periostin mRNA concentrations significantly increased with IL13 at these concentrations (Figure 3A).

Next, we examined the influence of dexamethasone and leflunomide on periostin mRNA production induced by IL13. As shown in Figure $3 \mathrm{~B}$ and $\mathrm{C}$, the increase in periostin mRNA expression caused by IL13 was significantly inhibited by dexamethasone and leflunomide.

Detection of STAT6 expression level in OA synoviocytes. STAT6 extracted from the OA synoviocytes in 96-well plates with IL13 was measured with commercially-available ELISA in experiments on the synoviocytes carried out as above for $24 \mathrm{~h}$. STAT6 levels are reported in relation to the mean fluorescence intensity (MFI) of intracellular total-STAT6 and phospho-STAT6 for the control group. Our results indicated that the STAT6 level significantly increased using 10 and 20 $\mathrm{ng} / \mathrm{ml} \mathrm{IL13} \mathrm{for} 24 \mathrm{~h}$ (Figure 4A).

Next, we examined influence of dexamethasone and leflunomide on periostin production induced by IL13. As shown in Figure 4B and C, the increase in periostin mRNA expression induced by IL13 was significantly inhibited by dexamethasone and leflunomide.

\section{Discussion}

Periostin, which is a matricellular protein belonging to the fasciclin family, is expressed in fibrous to solid connective tissues, such as the periosteum (18), tendons, periodontal ligaments (19), blood vessels, and heart valves (20). Experimentally, periostin-deficient mice exhibit delays in repair and remodelling of injured tissues, such as. bone 

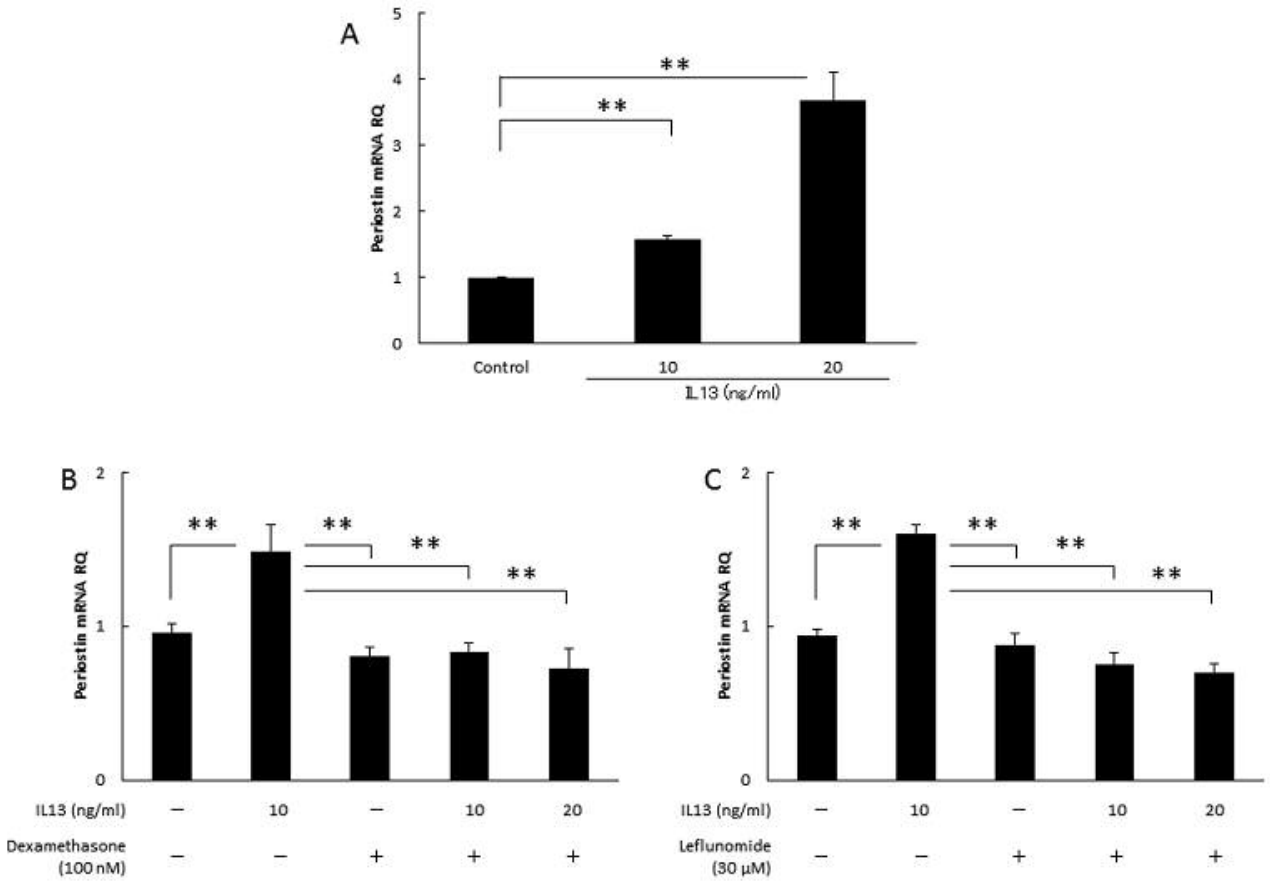

Figure 3. Effect of interleukin 13 (IL13) alone (A) and in combination with the anti-inflammatory dexamethasone (B) and signal transducer and activator of transcription 6 (STAT6) inhibitor leflunomide (C) on periostin mRNA expression in osteoarthritis (OA) synoviocytes. OA synoviocytes were cultured at a density of $1 \times 10^{4}$ cells in 96-well plate in triplicate with/without IL13 and treated or not with agent. Periostin mRNA expression was then determined after $24 \mathrm{~h}$ with quantitative reverse transcription polymerase chain reaction. Asterisks indicate statistically significant differences $(* * p<0.01)$. Error bars denote $\pm S D$. RQ: Relative quantification.

fractures (21). Periostin clearly plays crucial roles in tissue repair. However, in some cases, chronic or superabundant periostin expression can accelerate pathogenesis of tumours $(22,23)$, bronchial asthma $(24,25)$, atopic dermatitis $(26,27)$, polycystic kidney disease, and other fibrotic diseases (28). As recently reported, periostin promotes chronic inflammation by activating nuclear factor kappa B (NF-kB) signaling (26, $29,30)$. Periostin interacts with cells through various integrin pairs and is an essential downstream effector of several superfamily signaling pathways, such as IL4, IL13 and TGF$\beta(31,32)$. We showed that periostin was up-regulated in OA synovial fibroblasts and provided the first formal proof that periostin may be involved as an essential downstream effector of IL13 (11). However, there is no conclusive evidence because we did not observe a direct influence between periostin and IL13. Therefore, the main objective of our study was to clarify the influence of IL13 on periostin production, which is increased in patients with OA.

In the first experiment, we examined periostin mRNA/protein expression using human OA synoviocytes to investigate the influence of IL13 in OA pathology. We observed whether IL13 stimulation affected periostin secretion by synoviocytes of OA patient origin, including fibroblast, adipocyte, and cartilage cell, in vitro. We found production of periostin protein and mRNA increased in an IL13 concentration- and time-dependent manner (Figures 1 and 3). These results suggest that periostin expression occurs downstream of an IL13 cascade; additionally, the increase in periostin protein expression is concomitant with an increase in its mRNA (Figure 3).

IL13 is an immunoregulatory cytokine secreted predominantly by activated type- 2 helper T (TH2) cells. IL13 shares many functional properties with IL4, stemming from the fact that they share a common receptor subunit, the alpha subunit of the IL4 receptor (IL4R $\alpha$ ). IL13 mediates its effects by interacting with a complex receptor system comprising of IL4R $\alpha$ and two IL13 binding proteins, IL13R $\alpha 1$ and IL13R $\alpha 2$. However, unlike IL4, IL13 does not appear to be important in the initial differentiation of cluster of differentiation 4 (CD4) T-naive T-cells into TH2 cells, because there are no functional IL13 receptors on human Tcells (33-35). Rather, IL13 is related to fibrosis of tissue in various chronic types of inflammation because IL13Rs are expressed on endothelial cells, fibroblasts, and smooth muscle cells. The evidence that IL13 stimulation resulted in periostin production by OA synoviocytes in this study supports our previous in vivo observations indicating a parallel increase of IL13 and periostin expression in the 


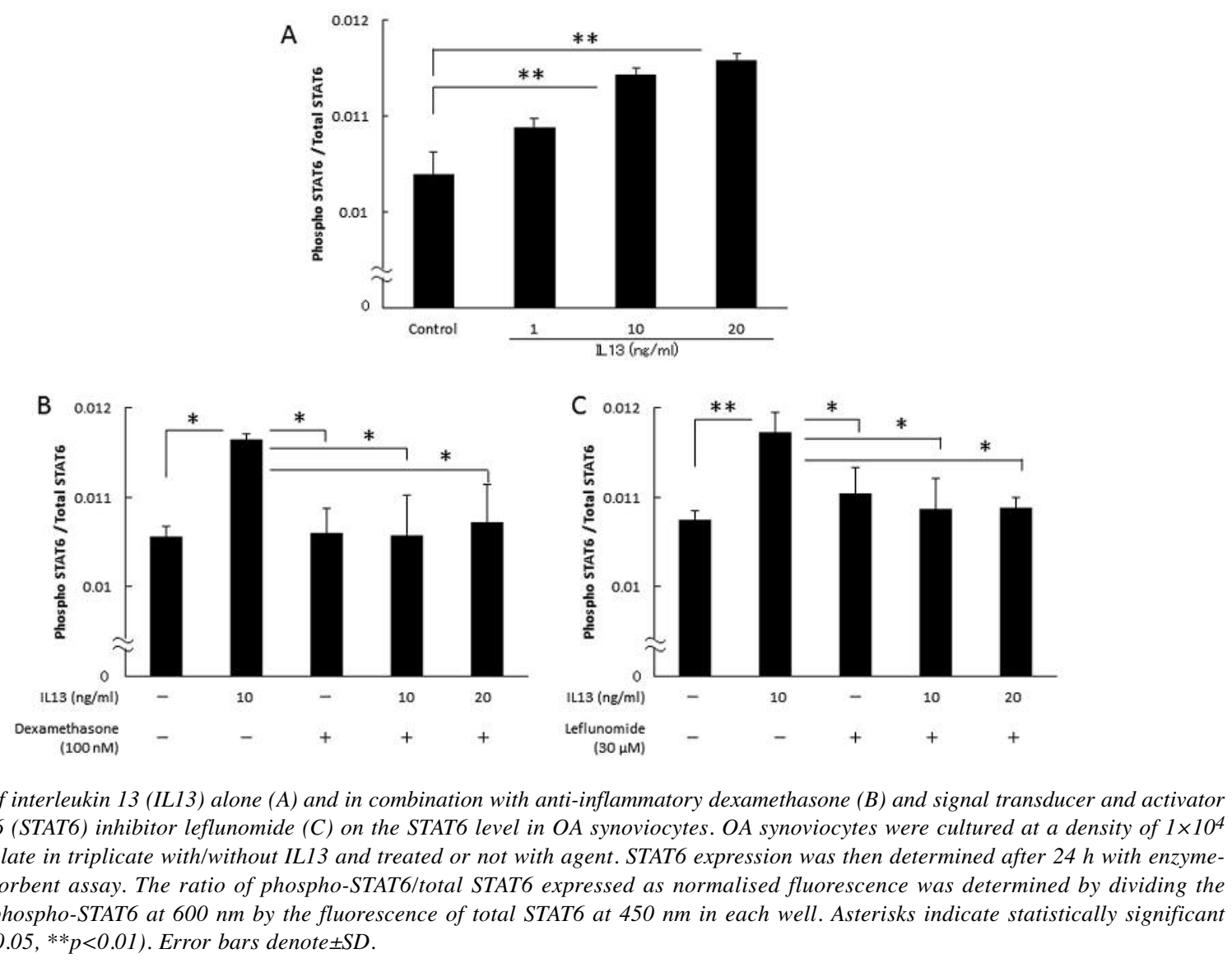

synovial fluid in OA. Furthermore, the addition of an immunosuppressive agent, dexamethasone, abolished the periostin-inducing effect of IL13 in OA synoviocytes (Figures 2A and 3B). These results provide evidence that IL13 might be an important effector molecule in regulation of periostin in OA signalling pathways.

Therefore, the purpose of the second phase of our experiments was to determine the location of IL13 action in signalling pathways. We observed that IL13 increased phosphorylation of STAT6 and activated STAT6 in OA synoviocytes in a dose-dependent manner (Figure 4A), and that the pan immunosuppressive agent dexamethasone abolished STAT6 activation induced by IL13 in OA synoviocytes (Figure 4B). Moreover, the treatment of OA synoviocytes with the STAT6 inhibitor leflunomide blocked production of both periostin protein and mRNA, as well as STAT6 activity, induced by IL13 (Figures 2B, 3C, and 4C). These data demonstrate that the TH2 cytokine IL13, inducing periostin production, functions through a STAT6-dependent mechanism. IL13 binds to the IL4/IL13R to activate STAT6, which plays a major role in mediating a variety of phenotypic endpoints in inflammation, including fibrosis $(36,37)$.
Periostin overexpression in progressive OA of the knee occurs by a mechanism through which MMP exacerbates the chronic breakdown of cartilage in the joints, as our preliminary research showed that periostin induced expression of MMP (11). Periostin modulation may provide an effective therapeutic strategy in OA via Janus kinase (JAK)-STAT signaling. It has become evident that IL13 and periostin are key mediators in the pathogenesis of chronic joint disease in OA. Accordingly, IL13 and periostin are attractive, novel therapeutic targets for pharmacological intervention in chronic inflammatory diseases, such as OA, and leflunomide may be one of the candidate's agents. In addition, intra-articularly injected glucocorticosteroid dexamethasone is a conventional treatment for OA. Steroids injected intra-articularly into the knees of patients with OA sometimes cause destruction of the articular surface, known as steroid-induced arthropathy (39). The principle of steroidinduced arthropathy is not known in detail, but steroid therapy is very effective for a treatment of acute-stage OA (38-40). Steroid treatment should be used within an optimal time-frame and niche and at the optimum dose. Intraarticular periostin may become a biomarker to ascertain the 
appropriateness of steroid treatment. It will be necessary to examine the various aspects of how periostin in synovial fluid influences the progression of OA.

\section{Conflicts of Interest}

The Authors declare that there is no conflict of interest in regard to this article.

\section{References}

1 Muraki S, Oka H, Akune T, Mabuchi A, En-yo Y, Yoshida M, Saika A, Suzuki T, Yoshida H, Ishibashi H, Yamamoto S, Nakamura K, Kawaguchi $\mathrm{H}$ and Yoshimura N: Prevalence of radiographic knee osteoarthritis and its association with knee pain in the elderly of Japanese population-based cohorts: the ROAD study. Osteoarthritis Cartilage 17: 1137-1143, 2009.

2 Attur M, Belitskaya-Lévy I, Oh C, Krasnokutsky S, Greenberg J, Samuels J, Smiles S, Lee S, Patel J, Al-Mussawir H, McDaniel G, Kraus VB and Abramson SB: Increased interleukin- $1 \beta$ gene expression in peripheral blood leukocytes is associated with increased pain and predicts risk for progression of symptomatic knee osteoarthritis. Arthritis Rheum 63: 1908-1917, 2011.

3 Hrnack SA and Barber FA: Managing the pain of knee osteoarthritis. Phys Sportsmed 42: 63-70, 2014.

4 Fibel KH, Hillstrom HJ and Halpern BC: State-of-the-art management of knee osteoarthritis. World J Clin Cases 3: 89$101,2015$.

5 Takeshita S, Kikuno R, Tezuka K and Amann E: Osteoblastspecific factor 2: cloning of a putative bone adhesion protein with homology with the insect protein fasciclin I. Biochem J 294: 271-278, 1993.

6 Conway SJ, Izuhara K, Kudo Y, Litvin J, Markwald R, Ouyang G, Arron JR, Holweg CT and Kudo A: The role of periostin in tissue remodeling across health and disease. Cell Mol Life Sci 71: 1279-1288, 2014.

7 Wu L and Parhofer KG: Diabetic dyslipidemia. Metabolism 63 1469-1479, 2014.

8 Parhofer KG: Interaction between glucose and lipid metabolism: more than diabetic dyslipidemia. Diabetes Metab J 39: 353-362, 2015.

9 Badman MK, Pissios P, Kennedy AR, Koukos G, Flier JS and Maratos-Flier E: Hepatic fibroblast growth factor 21 is regulated by PPAR $\alpha$ and is a key mediator of hepatic lipid metabolism in ketotic states.Cell Metab 5: 426-437, 2007.

10 Teunis T, Beekhuizen M, Van Osch GV, Schuurman AH, Creemers LB and van Minnen LP: Soluble mediators in posttraumatic wrist and primary knee osteoarthritis. Arch Bone Jt Surg 2: 146-150, 2014.

11 Ishikawa S, Asano K, Kusayanagi H, Takashima M, Yoshida N, Yamasaki E and Hisamitsu T: Influence of periostin on synovial fibroblasts in knee osteoarthritis. Chronic Dis Int 2: 1013, 2015.

12 Prota LF, Cebotaru L, Cheng J, Wright J, Vij N, Morales MM and Guggino WB: Dexamethasone regulates CFTR expression in Calu-3 cells with the involvement of chaperones HSP70 and HSP90. PLoS One 7: e47405, 2012.

13 Wang G, Guo Y, Zhou T, Shi X, Yu J, Yang Y, Wu Y, Wang J, Liu M, Chen X, Tu W, Zeng Y, Jiang M, Li S, Zhang P, Zhou Q, Zheng B, Yu C, Zhou Z, Guo X and Sha J: In-depth proteomic analysis of the human sperm reveals complex protein compositions. J Proteomics 79: 114-122, 2013.

14 Swartzman E, Shannon M, Lieu P, Chen SM, Mooney C, Wei E, Kuykendall J, Tan R, Settineri T, Egry L and Ruff D: Expanding applications of protein analysis using proximity ligation and qPCR. Methods 50: S23-26, 2010.

15 Barbacioru CC, Wang Y, Canales RD, Sun YA, Keys DN, Chan F, Poulter KA and Samaha RR: Effect of various normalization methods on Applied Biosystems expression array system data. BMC Bioinformatics 7: 533, 2006.

16 Martínez A, Sánchez-Lopez M, Varadé J, Mas A, Martín MC, de Las Heras V, Arroyo R, Mendoza JL, Díaz-Rubio M, FernándezGutiérrez B, de la Concha EG and Urcelay E: Role of the MHC2TA gene in autoimmune diseases. Ann Rheum Dis 66: 325-329, 2007

17 Kósa JP, Kis A, Bácsi K, Balla B, Nagy Z, Takács I, Speer G and Lakatos P: The protective role of bone morphogenetic protein-8 in the glucocorticoid-induced apoptosis on bone cells. Bone 48: 1052-1057, 2011.

18 Horiuchi K, Amizuka N, Takeshita S, Takamatsu H, Katsuura M, Ozawa H, Toyama Y, Bonewald LF and Kudo A: Identification and characterization of a novel protein, periostin, with restricted expression to periosteum and periodontal ligament and increased expression by transforming growth factor beta. J Bone Miner Res 14: 1239-1249, 1999.

19 Wilde J, Yokozeki M, Terai K, Kudo A and Moriyama K: The divergent expression of periostin mRNA in the periodontal ligament during experimental tooth movement. Cell Tissue Res 312: 345-351, 2003.

20 Oka T, Xu J, Kaiser RA, Melendez J, Hambleton M, Sargent MA, Lorts A, Brunskill EW, Dorn GW 2nd, Conway SJ, Aronow BJ, Robbins J and Molkentin JD: Genetic manipulation of periostin expression reveals a role in cardiac hypertrophy and ventricular remodeling. Circ Res 101: 313-321, 2007.

21 Nakazawa T, Nakajima A, Seki N, Okawa A, Kato M, Moriya H, Amizuka N, Einhorn TA and Yamazaki M: Gene expression of periostin in the early stage of fracture healing detected by cDNA microarray analysis. J Orthop Res 22: 520-525, 2004.

22 Kyutoku M, Taniyama Y, Katsuragi N, Shimizu H, Kunugiza Y, Iekushi K, Koibuchi N, Sanada F, Oshita Y and Morishita R: Role of periostin in cancer progression and metastasis: inhibition of breast cancer progression and metastasis by antiperiostin antibody in a murine model. Int $\mathrm{J}$ Mol Med 28: 181186, 2011.

$23 \mathrm{Ma} \mathrm{D}, \mathrm{Lu} \mathrm{H}, \mathrm{Xu} \mathrm{L}, \mathrm{Xu} \mathrm{X}$ and Xiao W: Mechanical loading promotes Lewis lung cancer cell growth through periostin: In Vitro Cell Dev Biol Anim 45: 467-472, 2009.

24 Takayama G, Arima K, Kanaji T, Toda S, Tanaka H, Shoji S, McKenzie AN, Nagai $H$, Hotokebuchi $T$ and Izuhara $K$ : Periostin: a novel component of subepithelial fibrosis of bronchial asthma downstream of IL-4 and IL13 signals. J Allergy Clin Immunol 118: 98-104, 2006.

25 Parulekar AD, Atik MA and Hanania NA: Periostin, a novel biomarker of TH2-driven asthma. Curr Opin Pulm Med 20: 60$65,2014$.

26 Masuoka M, Shiraishi H, Ohta S, Suzuki S, Arima K, Aoki S, Toda S, Inagaki N, Kurihara Y, Hayashida S, Takeuchi S, Koike K, Ono J, Noshiro H, Furue M, Conway SJ, Narisawa Y and Izuhara K: Periostin promotes chronic allergic inflammation in response to Th2 cytokines. J Clin Invest 122: 2590-2600, 2012. 
27 Shiraishi H, Masuoka M, Ohta S, Suzuki S, Arima K, Taniguchi $\mathrm{K}$, Aoki S, Toda S, Yoshimoto T, Inagaki N, Conway SJ, Narisawa $\mathrm{Y}$ and Izuhara K: Periostin contributes to the pathogenesis of atopic dermatitis by inducing TSLP production from keratinocytes. Allergol Int 61: 563-572, 2012.

28 Kashima TG, Nishiyama T, Shimazu K, Shimazaki M, Kii I, Grigoriadis AE, Fukayama M and Kudo A: Periostin, a novel marker of intramembranous ossification, is expressed in fibrous dysplasia and in c-Fos-overexpressing bone lesions. Hum Pathol 40: 226-237, 2009

29 Nishiyama T, Kii I, Kashima TG, Kikuchi Y, Ohazama A, Shimazaki M, Fukayama $M$ and Kudo A: Delayed reepithelialization in periostin-deficient mice during cutaneous wound healing. PLoS One 6: e18410. 2011.

30 Taniguchi K, Arima K, Masuoka M, Ohta S, Shiraishi H, Ontsuka K, Suzuki S, Inamitsu M, Yamamoto K, Simmons O, Toda S, Conway SJ, Hamasaki Y and Izuhara K: Periostin controls keratinocyte proliferation and differentiation by interacting with the paracrine IL-1alpha/IL-6 loop. J Invest Dermatol 134: 1295-1304, 2014.

31 Izuhara $\mathrm{K}$, Arima $\mathrm{K}$, Ohta S, Suzuki S, Inamitsu $\mathrm{M}$ and Yamamoto K: Periostin in allergic inflammation. Allergol Int 63: 143-151, 2014.

32 Walker JT, McLeod K, Kim S, Conway SJ and Hamilton DW: Periostin as a multifunctional modulator of the wound healing response. Cell Tissue Res 365: 453-465, 2016.

33 Hershey GK: IL13 receptors and signaling pathways: an evolving web. J Allergy Clin Immunol 111: 677-690, 2003.

34 Ferreira R, Lively S and Schlichter LC: IL-4 type 1 receptor signaling up-regulates KCNN4 expression, and increases the $\mathrm{KCa} 3.1$ current and its contribution to migration of alternativeactivated microglia. Front Cell Neurosci 8: 183, 2014.
35 Hebenstreit D, Wirnsberger G, Horejs-Hoeck J and Duschl A: Signaling mechanisms, interaction partners, and target genes of STAT6. Cytokine Growth Factor Rev 17: 173-188, 2006.

36 Finkelman FD, Hogan SP, Hershey GK, Rothenberg ME and Wills-Karp M: Importance of cytokines in murine allergic airway disease and human asthma. J Immunol 184: 1663-1674, 2010.

37 Ingram JL, Antao-Menezes A, Mangum JB, Lyght O, Lee PJ and Elias JA and Bonner JC: Opposing actions of Stat1 and Stat6 on IL13-induced up-regulation of early growth response-1 and platelet-derived growth factor ligands in pulmonary fibroblasts. J Immunol 177: 4141-4148, 2006.

38 Schumacher HR and Chen LX: Injectable corticosteroids in treatment of arthritis of the knee. Am J Med 118: 1208-1214, 2005.

39 Heard BJ, Barton KI, Chung M, Achari Y, Shrive NG, Frank CB and Bonner JC: Single intra-articular dexamethasone injection immediately post-surgery in a rabbit model mitigates early inflammatory responses and post-traumatic osteoarthritis-like alterations. J Orthop Res 33: 1826-1834, 2015.

40 Bellamy N, Campbell J, Robinson V, Gee T, Bourne R and Wells G: Intraarticular corticosteroid for treatment of osteoarthritis of the knee. Cochrane Database Syst Rev: CD005328, 2006.

Received November 4, 2016

Revised November 29, 2016

Accepted December 19, 2016 